\title{
Dynamic Performance of a Dual-Loop ControlledDC Shunt Motor with a Two-Quadrant DC Chopper
}

\author{
Elmer R. Magsino* Gerald P. Arada \\ Department of Electronics and Communications Engineering, \\ Gokongwei College of Engineering, De La Salle University, Manila, Philippines \\ "elmer.magsino@dlsu.edu.ph
}

\begin{abstract}
In learning and understanding liear control systems, DC motors can be utilized to display the various performance of a second-order system, since they can be bought off-the-shelf easily. DC motors are also used extensively in many applications, such as placing a blade on the motor shaft easily creates an electric fan. DC motors can also run in a clockwise or counterclockwise direction just by changing the voltage polarities applied to the motor terminals. However, this type of manual control is very tedious, introduces additional hardware, or exposes the DC motor to wear and tear. In this work, we implement the dual-loop control of a DC shunt motor under various loading conditions and direction of rotation. The inner and outer control loops correspond to the current and speed controllers of the system. Extensive simulation results verify the motor performance under various dynamic loading.
\end{abstract}

Key words: DC Motor Control, Two-Quadrant Chopper, Dual Loop PID Control, Matlab Simulink.

\section{INTRODUCTION}

Most household electrical equipment utilizes electric machines and uses the AC source. For remote-controlled toys, mini-fans, legged robots [1], and electric vehicles [2], DC motors are employed. Empirically, electric machines come in a variety of domestic, commercial, and industrial applications [3] and widely used. Some applications, such as mini-fans or remote-controlled toys, do not necessitate the use of complex control systems. They may function even if the system is in open loop. However, for more complex systems, such as in manufacturing [4] and cargo ports[5], control and protection schemes are essential. [6] mentioned that energy efficiency in DC motors in the absence of an accurate mathematical model and the presence of time-varying disturbances is a challenging problem.

In the field of robotics and electric vehicles, DC motors are most often used because of the source of electrical energy. It is in this nature that controlling the behavior of these DC motors is vital. The most common parameter that is controlled is its speed since the speed is easily monitored or visualized. DC motor control employs various control strategies such as sliding mode [7], predictive control [8], fuzzy logic [9], and PID [10]. These control strategies rely on the accurate modeling of the plant; therefore, they are good examples of undergraduate control engineering discussions.

In this work, we employ PI controllers to stabilize both the speed and torque of the DC shunt motor and will rely on the second-order mathematical models commonly used in DC shunt motors. In any DC motor experiment, the student observes the characteristics and performance at varying loads and speeds. In this light, this work allows students to simulate DC shunt motors and pre-determine the expected experimental results. Also, if the topic of controller design is targeted, then students can simply replace the controllers with their desired control structure. They can even remove the inner control loop to check the difference. The significantfindings of the study are enumerated below.

1. We develop an analytical model for the DC shunt motor and two-quadrant chopper to allow the motor to rotate in either the clockwise or counterclockwise direction. These models are converted into Simulink blocks for verification.

2. Simulation results verify the performance of the DC shunt motor under various dynamic loading conditions. Insights can be derived from these extensive simulation results.

Thepresentation of the paper is as follows: Section II presents the system model and preliminaries used in developing the DC motor model, chopper, and controller. Section III shows the results of the analytical model under various loading conditions. Lastly, the paper is concluded in Section IV.

\section{SYSTEM MODEL AND PRELIMINARIES}

This section discusses the modeling of the DC motor, two-quadrant chopper, and the design of the dual loop PID controllers. 


\subsection{Shunt Motor Modeling}

The dual-loop control of a two-quadrant DC chopper DC motor control is shown in Figure 1. Under various acceptable loading conditions, the desired speed is in the range $-150 \leq \omega_{m} \leq 150 \mathrm{rpm}$, i.e., the DC motor can run in either the clockwise or counterclockwise direction. The inner loop is the current controller and runs at a faster rate than the outer loop, which is the speed controller.

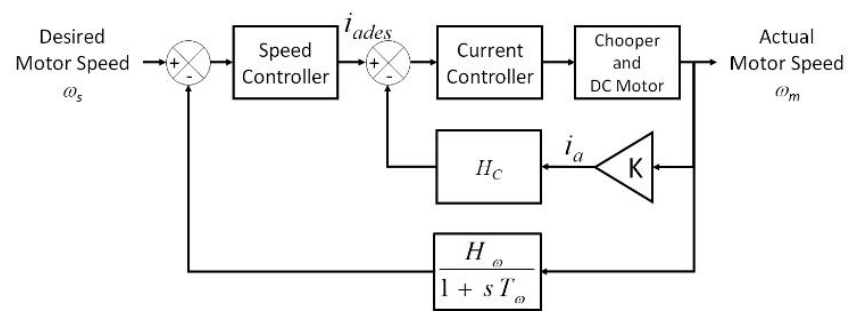

Figure 1: Dual loop control of a two-quadrant DC Shunt Motor.

DC Shunt motors are ideally used in machine tools and pumps because they can achieve a constant speed from no load to full load. The speed and position of DC shunt motors are easily controllable[11]. The DC Shunt motor modeling and its electro-mechanical relationships follow the derivations in [6]. The field current is constant, and the armature current, $i_{a}$, is controlled to vary the speed accordingly given various loading conditions.

A two-quadrant DC Chopper shown in Figure 2 is employed to control the direction of rotation of the DC Shunt motor. This Class D chopper maintains a positive output current while changing the voltage sign during rotation. In the circuit, when $\mathrm{T} 1$ and $\mathrm{T} 2$ are turned $\mathrm{ON}$ (D1 and D2 are OFF), the current flows through the resistive load in a clockwise direction. This current flow induces a voltage with polarities given. However, when D1 and D2 are turned ON (T1 and T2 are $\mathrm{OFF}$ ), the supply voltage $\mathrm{V}_{\mathrm{S}}$ changed sign. The current flow is still the same, but the voltage across the resistive load is reversed.

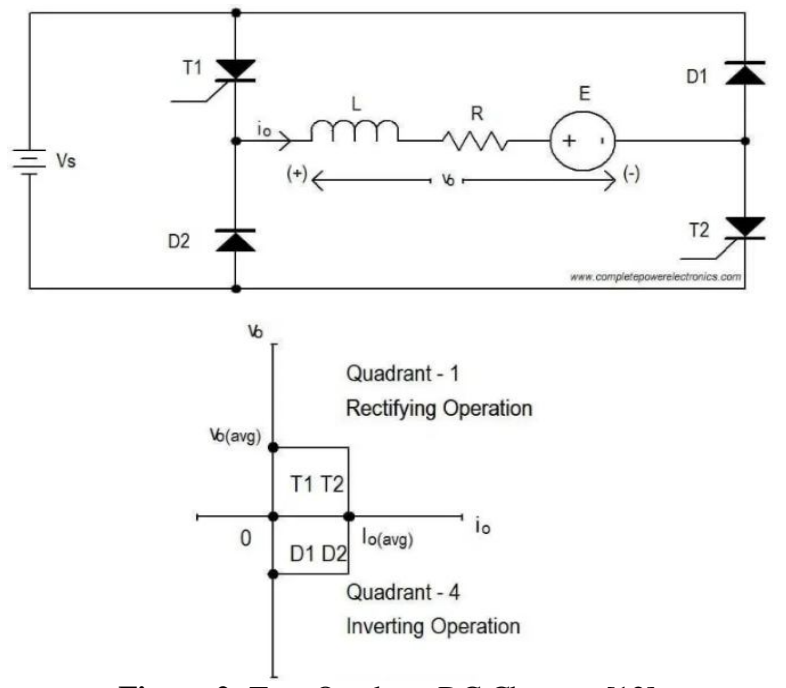

Figure 2: Two Quadrant DC Chopper [12]
The Class D chopper is mathematically modeled in (1), where $V_{\text {out }}$ represents the voltage across the L, R, and E ofFigure 2 .

$$
V_{\text {out }}=D V-(1-D) V
$$

where $V$ is the input DC voltage, $D$ is either 1 or 0 . The chopper turns a constant DC supply into an AC rectangular switching signal. $D=1$ outputs a positive voltage, while $D=0$ produces a negative voltage. Effectively, the ratio of the duration on how long $D=1$ and total time $(D=1$ and $D=0)$ is equivalent to the duty cycle.

\subsection{Design of the Controllers for Speed and Torque}

The design of the dual loop controllers employs Proportional-Integral-Derivative (PID) controllers[10, 13, 14]. For various loading conditions, the designed controller adjusts the value of the armature current accordingly, $i_{a}$. During start-up, the current controller can prevent damage to the DC motor when there is a large armature current. The inner loop monitors the armature current because it changes faster than the voltage since the voltage loop has a rectangular voltage input, while the armature current is triangular.

In this study, the current controller employs a PI compensator in the form of (2), where $K_{C}$ and $T_{C}$ are the current controller gains.

$$
G_{c}(s)=\frac{K_{c}\left(1+s T_{c}\right)}{s T_{c}}
$$

The speed controller or the outer loop ensures that the DC shunt motor is rotating at the desired angular speed regardless of the load connected to the shaft. The speed control utilizes a PI controller in (3), where $K_{S}$ and $T_{S}$ are the speed controller gains.

$$
G_{s}(s)=\frac{K_{s}\left(1+s T_{s}\right)}{s T_{s}}
$$

The current and speed feedback transfer functions are gain and low pass filter, respectively. The current feedback gain only samples the armature current so as the triangular waveform is maintained. On the other hand, the low pass filter centered at 100 radians/sec is to remove high-frequency noises.

\section{SIMULATION RESULTS AND DISCUSSION}

The DC shunt motor is rated at $1.5 \mathrm{HP}$ with a speed of 1800 rpm. Table 1 shows the DC motor parameters used in the simulation, and these parameters are strictly similar topractical DC motor values. 
Table 1 :DC Shunt Motor Parameters

\begin{tabular}{|l|c|}
\hline Motor Parameter & Value \\
\hline Viscous damping coefficient, $B_{1}$ & $0.01 \mathrm{~N}-\mathrm{m} / \mathrm{rad} / \mathrm{sec}$ \\
\hline Friction, $B_{t}$ & $0.0769 \mathrm{~N}-\mathrm{m} / \mathrm{rad} / \mathrm{sec}$ \\
\hline Inertia, $J$ & $0.0607 \mathrm{~kg}-\mathrm{m}^{2}$ \\
\hline Motor Constant, $K_{V}$ & $1.26 \mathrm{~V} / \mathrm{rad} / \mathrm{sec}$ \\
\hline Armature Resistance, $R_{a}$ & $4 \mathrm{ohms}$ \\
\hline Armature Inductance, $L_{a}$ & $0.072 \mathrm{H}$ \\
\hline
\end{tabular}

The dual-control of the DC shunt motor is simulated in Matlab Simulink. The block diagram in Figure 1 is transformed into the Simulink model shown in Figure 3. The current and speed controller gains are derived by using the Matlab Control Toolbox [15].

Thesoft-start block allows the motor speed to ramp up slowly so it can protect the DC shunt motor from too much current flow.

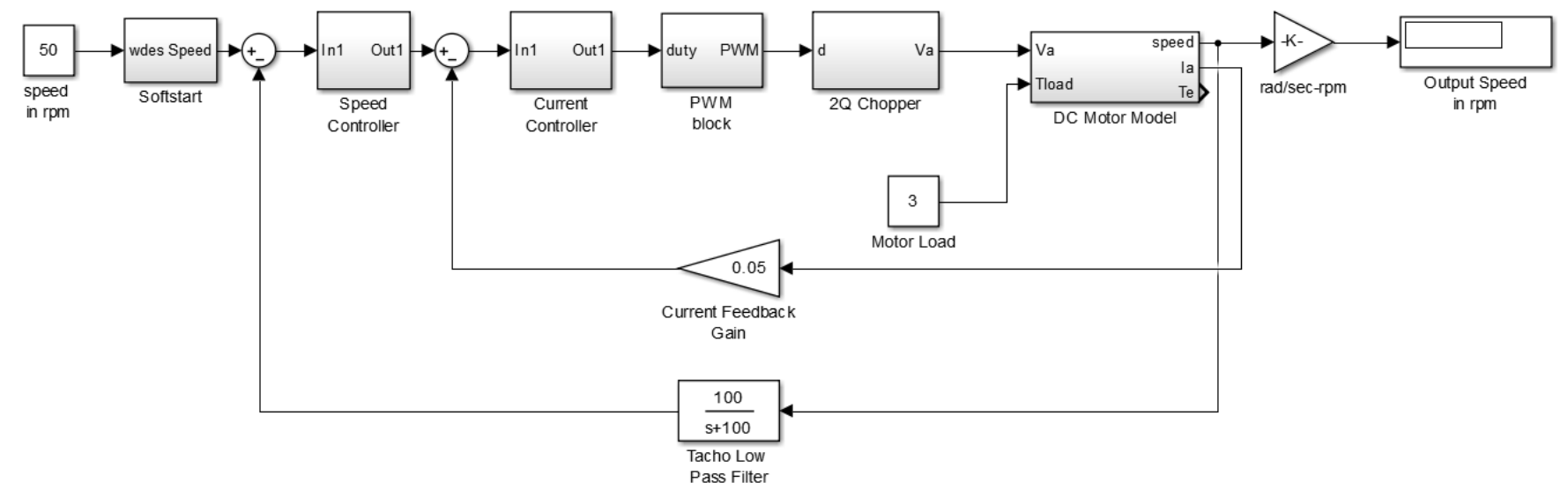

Figure 3: Matlab Simulink representation of the dual-loop control of a DC shunt motor with a two-quadrant chopper for the direction of rotation.

\subsection{Constant Load and Variable Speed}

Figure 4 and Figure 5illustrate the simulated DC shunt motor when the speed is changed from 100 to $150 \mathrm{rpm}$ and -100 to $-150 \mathrm{rpm}$, respectively. The load is at $3 \mathrm{~N}-\mathrm{m}$. For both directions, the transient response lasts about $0.5 \mathrm{sec}$, with the positive speed having a smaller value of transient than when a negative speed is applied. The average of armature current is equal to the set load of $3 \mathrm{~N}-\mathrm{m}$.

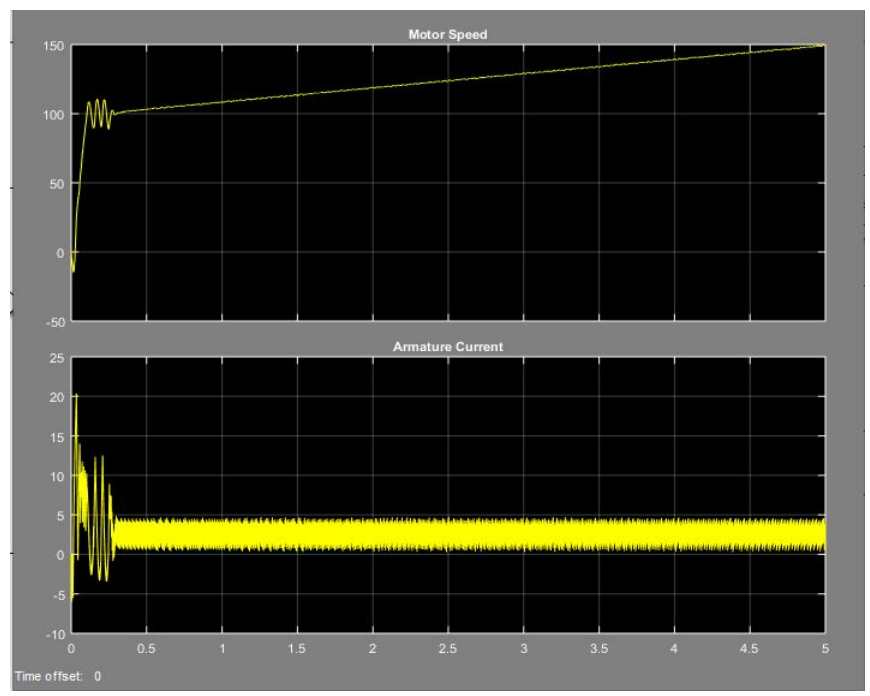

Figure 4: Constant load at $3 \mathrm{~N}-\mathrm{m}$ with variable speed from $100-$ $150 \mathrm{rpm}$.

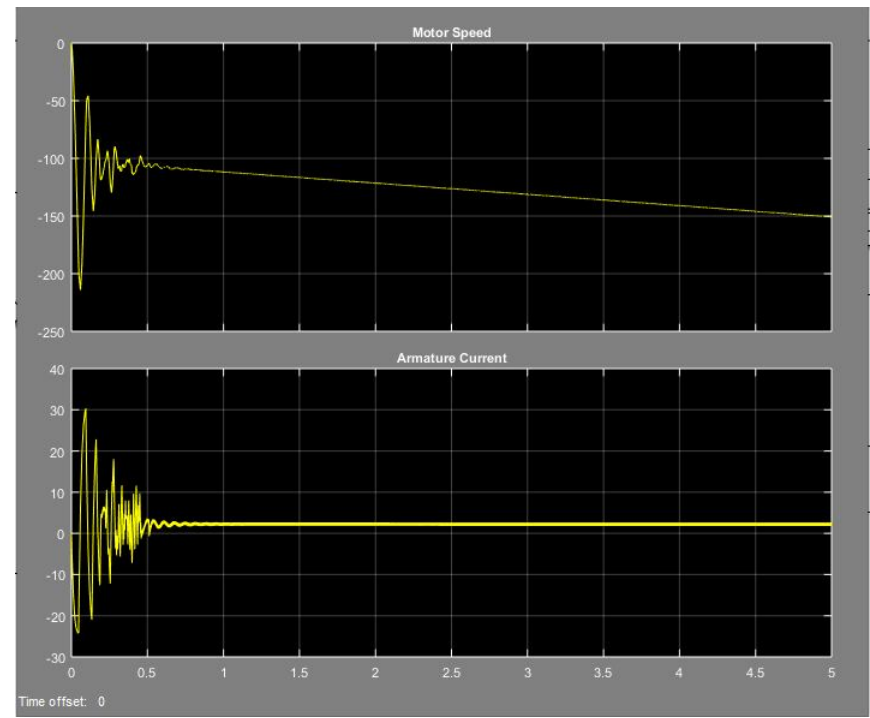

Figure 5: Constant load at $3 \mathrm{~N}-\mathrm{m}$ with variable speed from -100 $-150 \mathrm{rpm}$.

\subsection{Constant Speed, Variable Load}

Figure 6 and Figure 7show the DC shunt motor response when the load is changed from no load $(0 \mathrm{~N}-\mathrm{m})$ to full-load $(3 \mathrm{~N}-\mathrm{m})$. The control can follow the dynamic loading but has a higher ripple when there is a full load. This ripple of the armature current during dynamic loading is the same response even when there is a static loading of $3 \mathrm{~N}-\mathrm{m}$. 


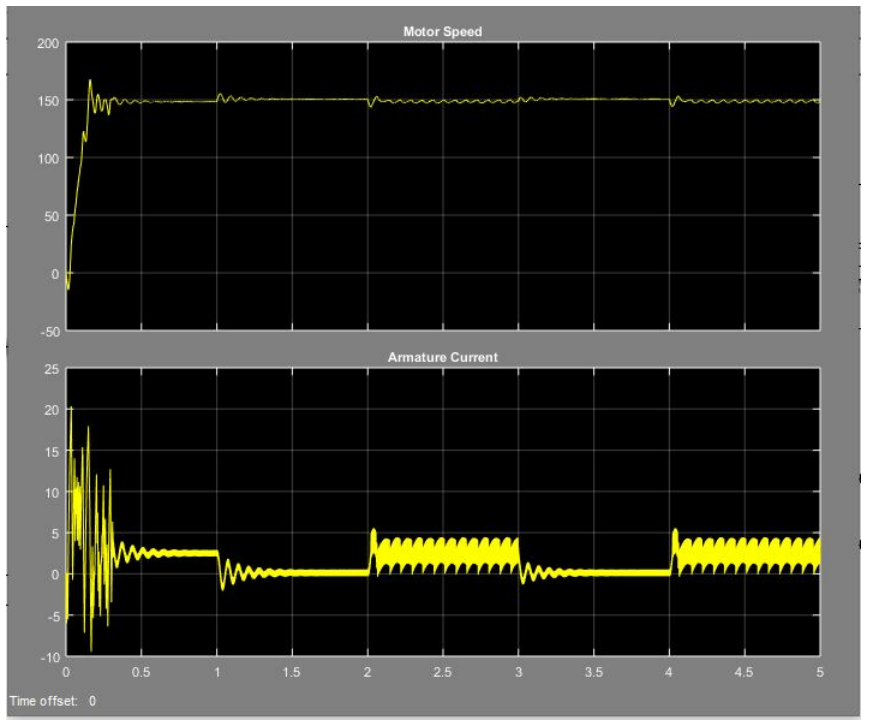

Figure 6: Rectangular load of $0-3 \mathrm{~N}-\mathrm{m}$, with a constant speed of $150 \mathrm{rpm}$.

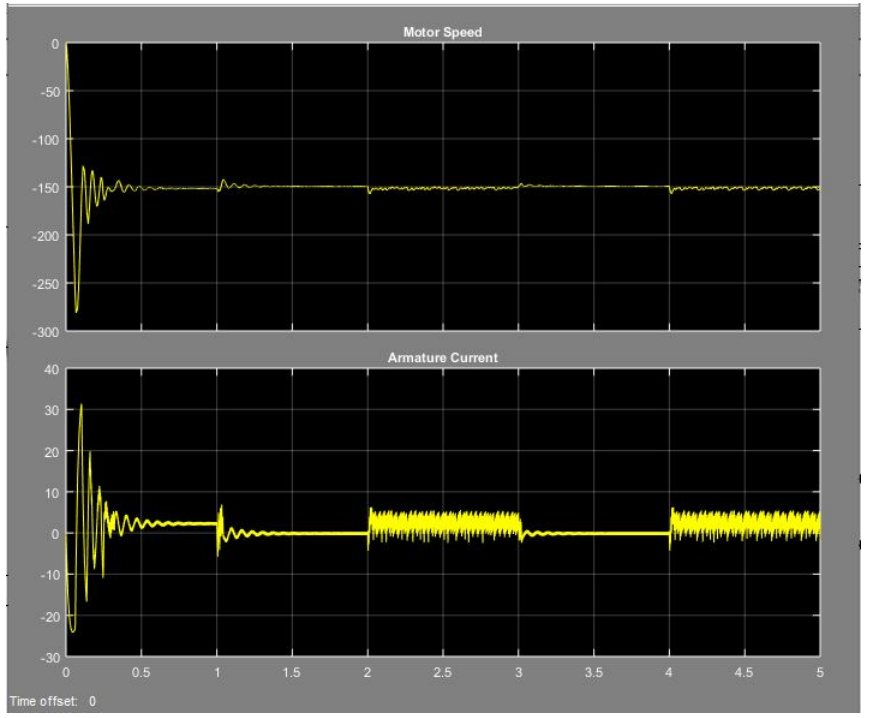

Figure 7: Rectangular load of $0-3 \mathrm{~N}-\mathrm{m}$, with a constant speed of $-150 \mathrm{rpm}$.

\subsection{Variable Speed, Variable Load}

We next simulated the scenario where both the input speed and load are dynamically changing, even though this scenario is highly impractical. Figure 8 shows the motor response during this type of loading. The motor speed (top part of Figure 8) depicts a smaller overshoot during the transition from a clockwise to a counterclockwise direction. However, the current response portrays the opposite reaction. A large current is needed to overcome the state of the DC motor, i.e., to reverse the rotation, the control system has to introduce a larger armature current. This large current is the reason why for DC motors, a dead time is needed before allowing the DC motor to rotate in the other direction. Another means of stopping the DC motor is through dynamic braking [16]. Dynamic braking can be done by turning D2 and T2 ON simultaneously while the input voltage is $0 \mathrm{~V}$. When the voltage across the chopper is removed, the motor acts as a generator. Therefore, the loop formed by the motor, D2, and $\mathrm{T} 2$ becomes a low-impedance path that results to the motor braking in its current direction.

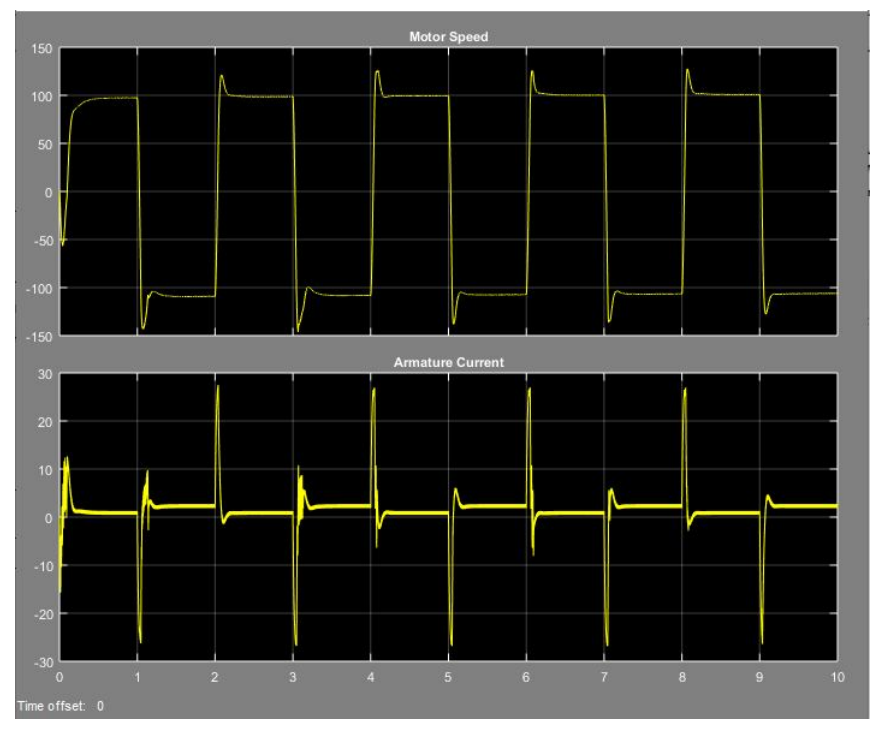

Figure 8: Rectangular speed input of $100--100 \mathrm{rpm}$, with a rectangular load input of. $1-3 \mathrm{~N}-\mathrm{m}$.

\subsection{Shunt Motor Characteristic Curves}

DC motors are evaluated by their characteristic curves. These curves show the relationship between speed, armature current, and load torque. Figure 9throughFigure 11 illustrate the dual-loop two-quadrant chopper controlled DC shunt motor behaviors.

Figure 9 shows the torque-speed relationship of the dual-loop controlled DC shunt motor. As the load (torque) increases, the two-quadrant DC shunt motor still maintains its constant speed.

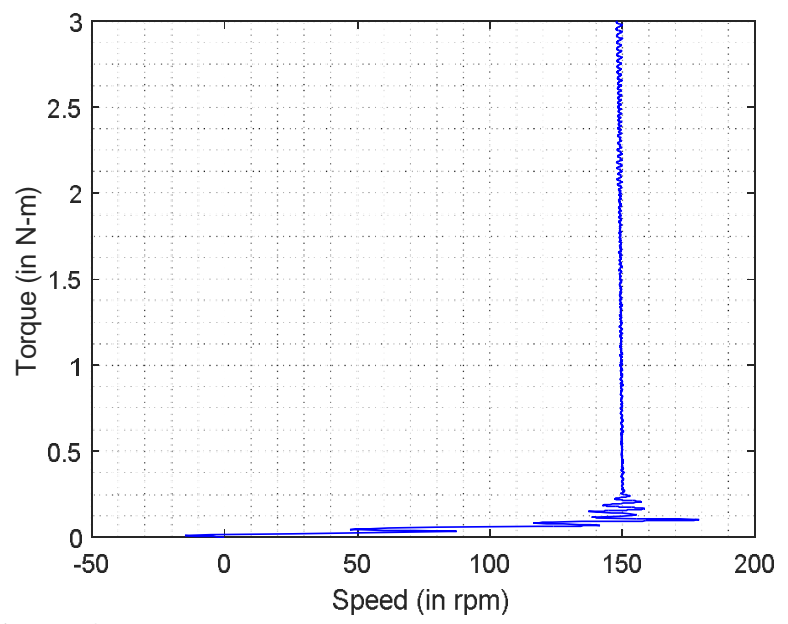

Figure 9: Torque vs. Speed performance curve of the two-quadrant DC shunt motor. 
Elmer R. Magsino et al., International Journal of Emerging Trends in Engineering Research, 8(8), August 2020,4312 - 4317

Figure 10 shows the same constant speed at varying load as the armature current is varied. In order for the DC shunt motor to maintain the speed at a given load, the speed and current (torque) controllers compute for the appropriate duty cycle to manipulate the chopper.

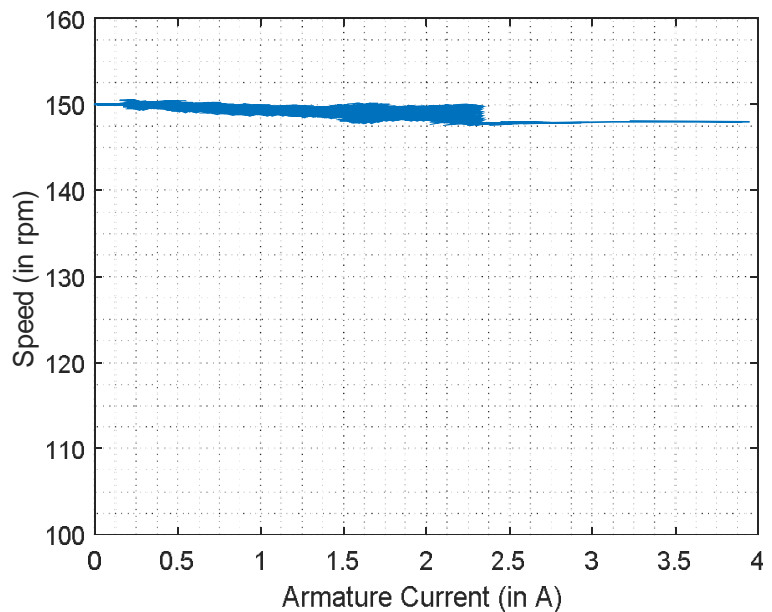

Figure 10: Speed vs. Current performance curve of the two-quadrant DC shunt motor.

Finally, Figure 11 illustrates how much armature current is changed to maintain constant speed at various loads. In the system under study, the torque and armature current has a ratio almost equal to one. This torque-current relationship can be adjusted by tuning the controller gains.

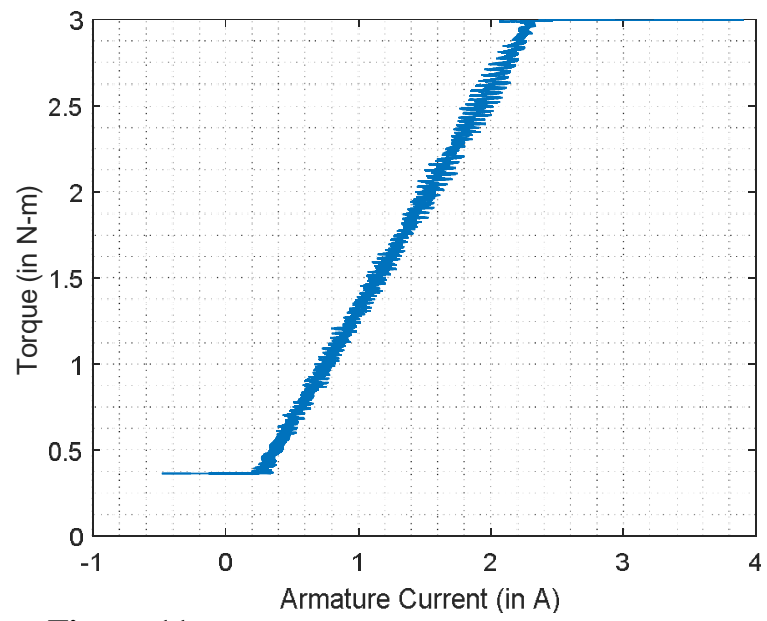

Figure 11: Torque vs. Current performance curve of the two-quadrant DC shunt motor.

\section{CONCLUSION AND FUTURE WORK}

In this study, we have implemented a dual-loop control of a DC shunt motor employing a two-quadrant chopper to control the motor's direction of rotation. The inner loop monitors and adjusts according to the armature current readings because of the current changes at a faster rate than the angular speed of the motor. The outer loop senses the actual angular speed and outputs the correct armature current value for the current controller to follow. Extensive simulation has verified all the crucial characteristics and performance curves of a DC shunt motor. Simulation results also show the performance of the dual-loop control structure in response to varying dynamic inputs in terms of torque load and desired motor speed.

In the future, we would like to incorporate energy anomaly detection [17] to monitor overspeeding or overloading of the DC motor.

\section{REFERENCES}

1. F. MohdIsharudden, H. Mohamed, Z. M. Rafaai, T. Y. W. Ho and M. S. Kamarudin, "Design and Prototyping of a Motorized Legged Robot with Klann Linkage Mechanism," International Journal of Emerging Trends in Engineering Research, vol. 8, no. 5, pp. 1941-1945, 2020. https://doi.org/10.30534/ijeter/2020/77852020

2. K. Sundararaman, R. Elavarasu and K. V. Bindu, "A Soft-Switched Bi-directional DC-DC Converter for a BLDC motor based Electric Vehicle," International Journal of Emerging Trends in Engineering Research, vol. 8, no. 6, pp. 2271-2277, 2020.

https://doi.org/10.30534/ijeter/2020/11862020

3. J. Sun, Y. Chai, C. Su, Z. Zhu and X. Luo, "BLDC motor speed control system fault diagnosis based on LRGF neural network and adaptive lifting scheme," Applied Soft Computing, vol. 14, pp. 609-622, 2014.

4. M. Ramadiansyah and W. Wahab, "Modelling, simulation and control of a high precision loading-unloading robot for CNC milling machine," in 2017 15th International Conference on Quality in Research (QiR): International Symposium on Electrical and Computer Engineering, 201.

5. B. Dragovic, E. Tzannatos and N. K. Park, "Simulation modelling in ports and container terminals: literature overview and analysis by research field, application area and tool," Flexible Services and Manufacturing Journal, vol. 29, no. 1, pp. 4-34, 2017.

6. R. Tapia-Olvera, F. Beltran-Carvajal, O. Aguilar-Mejia and A. Valderrabano-Gonzalez, "An adaptive speed control approach for DC shunt motors," Energies, p. 961, 2016.

7. J. Cabiles-Magsino and E. Magsino, "Reducing Beat Frequency Oscillation in a Two-phase Sliding Mode-controlled Voltage Regulator Module," Indonesian Journal of Electrical Engineering and Informatics (IJEEI), vol. 8, no. 1, pp. 52-62, 2020.

8. V. Lechappe, O. Salas, J. De Leon, F. Plestan, E. Moulay and A. Glumineau, "Predictive control of disturbed systems with input delay: experimental validation on a DC motor," IFAC-PapersOnLine, vol. 48, no. 12, pp. 292-297, 
2015.

https://doi.org/10.1016/j.ifacol.2015.09.393

9. E. R. Magsino, K. Obias, J. P. Samarista, M. F. Say and J. A. Tan, "A redundant flight recovery system implementation during an octocopter failure," in 2016 IEEE Region 10 Conference (TENCON), 2016.

10. E. Magsino, C. Dollosa, S. Gavinio, G. Hermoso, N. Laco and L. A. Roberto, "Stabilizing quadrotor altitude and attitude through speed and torque control of BLDC motors," in 2014 13th International Conference on Control Automation Robotics \& Vision (ICARCV), Singapore, 2014.

11. W. Elsrogy, M. A. Fkirin and M. Hassan, "Speed control of DC motor using PID controller based on artificial intelligence techniques," in 2013 International Conference on Control, Decision and Information Technologies (CoDIT), 2013.

12. "How Class D Chopper Works?," 23 April 2017. [Online]. Available:

http://www.completepowerelectronics.com/class-d -chopper-working-operation/. [Accessed 14 August 2020].

13. G. P. T. Mayuga and E. R. Magsino, "Adaptive Cruise Control Employing Taillight Tracking for a Platoon of Autonomous Vehicles," International Journal of Advanced Trends in Computer Science and Engineering, vol. 8, no. 3, pp. 640-645, 2019.

14. E. Magsino, "A WALKING BIPEDAL ROBOT USING A POSITION CONTROL ALGORITHM BASED ON CENTER OF MASS CRITERION," ARPN Journal of Engineering and Applied Sciences, vol. 14, no. 11, pp. 2029-2038, 2019.

15. J. Cabiles-Magsino and E. Magsino, "SPEED AND TORQUE CONTROL OF A DC SHUNT MOTOR," in 2009 NOCEI, 2009.

16. F. Faisal, M. M. Nishat and M. R. Mia, "An Investigation on DC Motor Braking System by Implementing Electromagnetic Relay and Timer," in 2019 International Conference on Electrical, Computer and Communication Engineering (ECCE), 2019. https://doi.org/10.1109/ECACE.2019.8679225

17. E. Magsino, "Energy Monitoring System Incorporating Energy Profiling and Predictive Household Movement for Energy Anomaly Detection," International Journal of Emerging Trends in Engineering Research, vol. 7, no. 8, pp. 151-156, 2019. https://doi.org/10.30534/ijeter/2019/08782019 